\title{
Exploring the Design Space of InterActive Urban Environments
} \section{triggering physical activity through embedded technology}

Loes van Renswouw

Eindhoven University of Technology Eindhoven, the Netherlands

I.m.v.renswouw@tue.nl

\section{Steven Vos}

Eindhoven University of Technology; Fontys University of Applied Sciences, Eindhoven, the Netherlands s.vos@tue.n
Pieter van Wesemael

Eindhoven University of Technology,

Eindhoven, the Netherlands

p.j.v.v.wesemael@tue.n

\section{Carine Lallemand}

Eindhoven University of Technology, Eindhoven, the Netherlands; University of Luxembourg, Esch-sur-Alzette, Luxembourg, c.e.lallemand@tue.nl

\section{ABSTRACT}

Promoting healthy lifestyles is an essential endeavor for public health. The design of active urban environments can be an effective medium to nudge people into moving. With technology increasingly integrated into our daily lives, designers have access to more data than ever. In this pictorial, we explore the design space of interActive environments (contraction of 'interactive' and 'active'); places designed to increase the physical activity of users or passers-by through the use of interactive technology. Through sketches, a benchmark of existing concepts and an analysis of designed artefacts, we map the different intervention levels, interaction modalities, behavior change strategies and technological opportunities to design such interActive environments. With this work, we invite the community to consider how digital technology can help understand and shape human behavior in urban environments, and provide inspiration to designers and practitioners.

Permission to make digital or hard copies of part or all of this work for personal or classroom use is granted without fee provided that copies are not made or distributed for profit or commercial advantage and that copies bear this notice an the full citation on the first page. Copyrights for third-party components of thi work must be honored. For all other uses, contact the Owner/ Author.

DIS '21, June 28-July 2, 2021, Virtual Event, USA C 2021 Copyright is held by the owner/author(s). ACM ISBN 978-1-4503-8476-6/21/06.

c) (i) $\Theta$

This work is licensed under a Creative Commons AttributionNonCommercial-NoDerivs International 4.0 License.

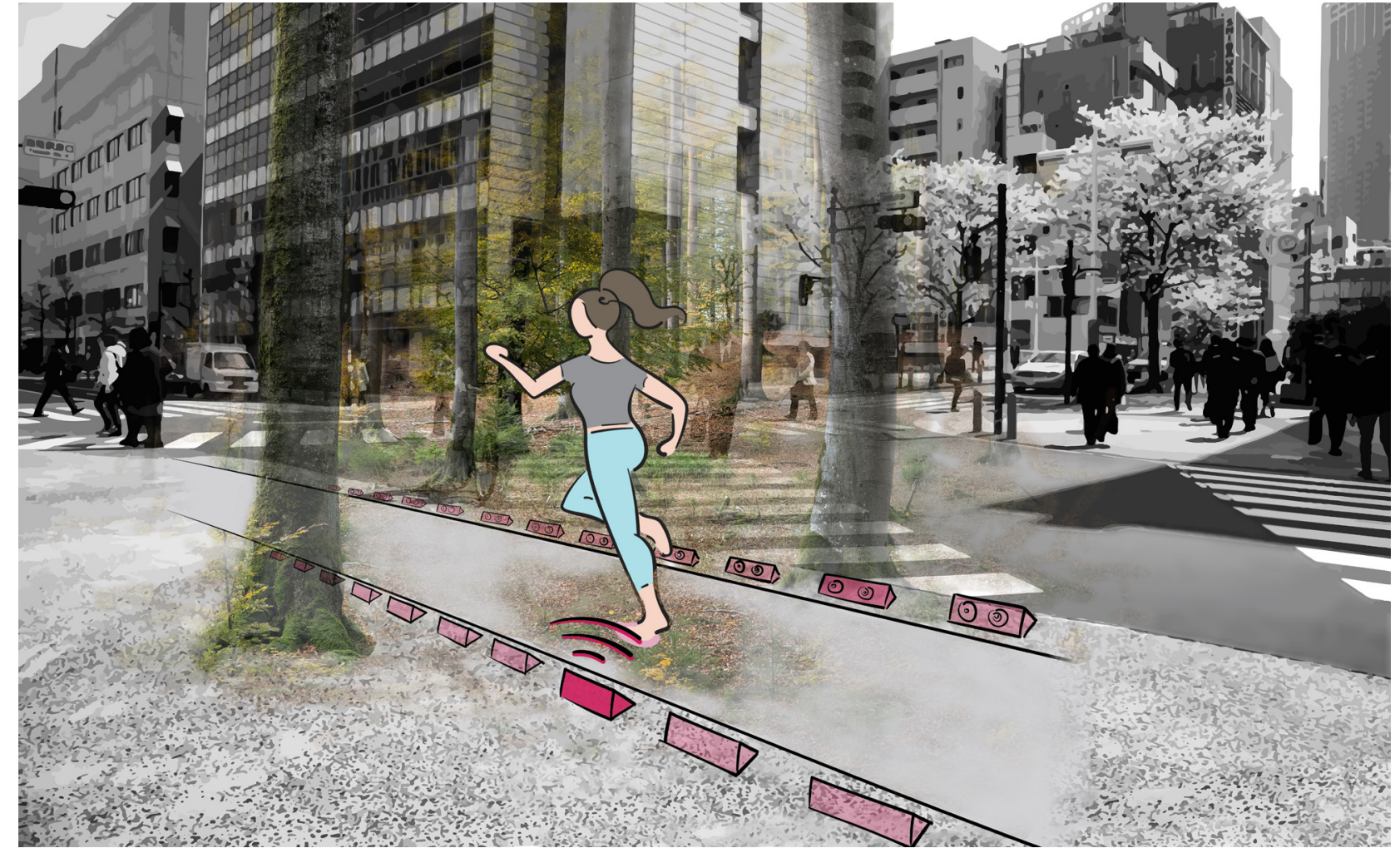

Authors Keywords

InterActive environment; Urban environment; Physical activity; Design space; Interactive Technology.
CSS Concepts

- Human-centered computing Interaction design Interaction design process and methods 


\section{INTRODUCTION}

Physical inactivity and the resulting health concerns are a key societal challenge in modern western societies [4][21][41]. Promoting healthy and active lifestyles is thus a timely topic for public policies as well as across multiple research fields. In this pictorial, we address physical inactivity specifically, which is influenced by a combination of individual, social and environmental factors [16][17]. Design of 'activating' urban environments can be an effective trigger to subconsciously nudge people into moving [34]][23]. Within the design community, we see opportunities in the field of active environment design [14][22], as well as in the ongoing shift towards Human-Environment Interaction (HEI)[37][39], where technology is increasingly integrated in the environment and is therefore omnipresent while less noticeable. These smart environments also allow for new types of feedback [37], and new levels of personalization of the environment, also an important factor in persuasive technology [3].

In this pictorial, we explore the design space of interActive environments, which we define as interactive environments that encourage physically activity behaviours, focusing on three aspects: the interaction modality, the intervention strategy and the technology used. Through our research, we investigate the potential of embedding interaction into the environment to engage a broad audience of users, including those who did not consciously decide to work out or download an activity app. Therefore, these 'accidental' encounters can broaden the impact of design interventions for physical activity, by involving a hard to reach but important target group.

A number of commercial solutions, public installations and exploratory prototypes that use technology in the outdoor environment as a trigger for physical activity have been designed, but to the best of our knowledge these efforts have yet not been drawn together or analyzed on a broader scale.

The presented design space exploration combines the results of a (1) benchmark of existing active environments, partly based on expert interviews, (2) sketching explorations with industrial design researchers and students, and (3) four use case analyses. This illustrated analysis of the design space of interActive environments is meant to inspire researchers and designers, and to pave the way for new designs and applications, optimizing the role of technology to shape meaningful experiences.

\section{BENGHMARK}

We started our design space exploration by benchmarking existing interActive environments, places purposely designed to increase the physical activity of users or passers-by through the use of interactive technology. In addition, we conducted semi-structured interviews with 11 professionals involved in the design of interActive environments. We purposely combined perspectives from different disciplines, including industrial designers $(n=4)$, architects and urban planners $(n=3)$, policy makers $(n=4)$, some of them being also design researchers. In addition to our own benchmark, we asked each of these experts to provide us with typical examples of active urban environments, ideally including an interactive/ technological component. These examples were discussed during the interview to understand what characteristics made them suitable to be described as active environments, which strategies were used to trigger people to be more active, what were the gaps in the design space especially related to the use of technology and data, and the underlying challenges for future development in this area.

Out of our scope are the numerous active environments which do not make use of technology (e.g., healthy routes, bare foot paths, walking meeting routes), rely solely on mobile technology without any intervention in the physical environment, as well as installations that specifically target children (e.g., smart playground design). Smartphone apps that use the physical environment [Figure A] in the context of sports

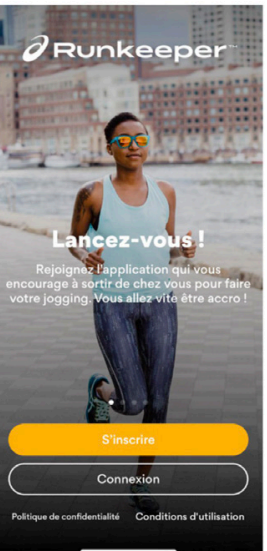
with physical activity and connected to the physical environment. fltr: Runkeeper [15], Strava [38], Pokémon Go [29] and Zombies, Run! [36] training (e.g., visualizing one's running route) or location-based exergames (e.g. Pokémon GO [29]) gained popularity in the last decade. While these make use of the physical environment (e.g., PokéStops in Pokémon GO are located on points of interest in the real world) or even augment it using Augmented Reality, they are not in the scope of interActive environments as no actual artefact nor technology is placed in the real world. Playground design increasingly make use of technologica components in order to promote cognitive, social and moto skills development [13]. While these outdoor play technologies might be relevant to consider, we narrowed our scope down to design concepts not targeted at this specific children audience.

Our benchmark allows us to distinguish several categories of designs, illustrated and annotated in the following pages: public recreational sports environments, temporary high-tech sports facilities, interactive public installations and active office environments. Noteworthy, we also found an important number of student and research projects conducted at design universities within interaction design or interactive environments curriculums. These numerous prototypes, while showcasing innovative properties, however remain at a conceptual stage, and are usually not deployed nor implemented in the public space. Benchmarking existing designs is worthwhile to understand success factors, challenges or limitations, as well as identifying the gaps and future design opportunities.

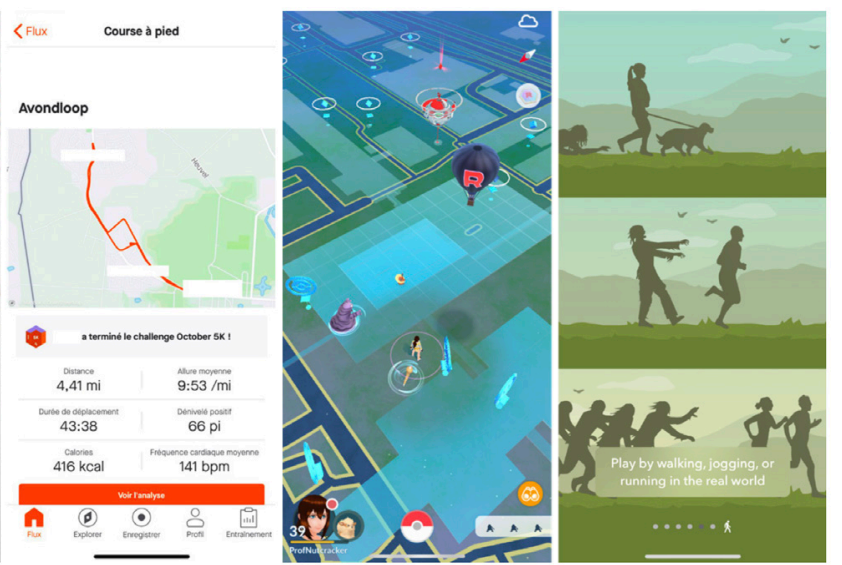




\section{BENGHMARK ON INTER-ACTIVE ENURONMENTS}

\section{Public recreational sport environments}

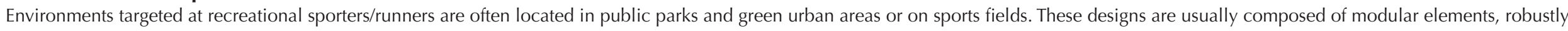

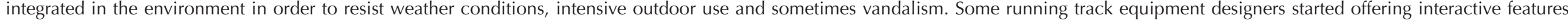
supporting training, mostly focused on athletic performance or serving accessibility purposes.

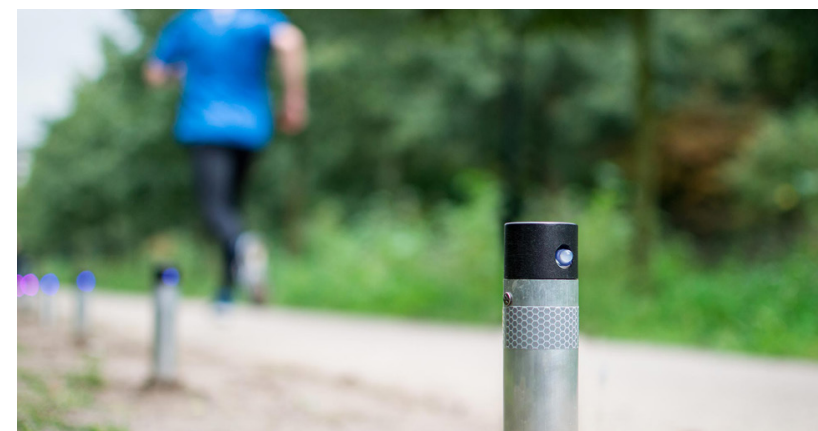

Run! [28]

Run! is a High-tech running track along a popular public running route. Through an adaptive light system it stimulates a more intense training and inspires (more) people to exercise.

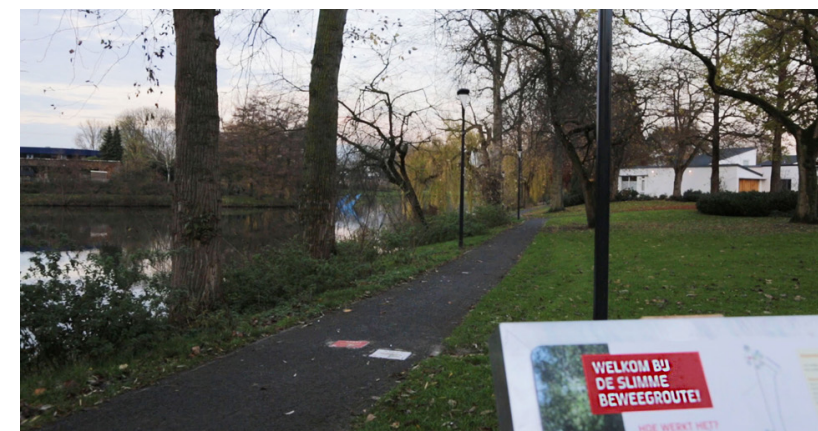

Slimme Beweegroute [9]

The Slimme Beweegroute ('Smart Exercise Route') is a $1.8 \mathrm{~km}$ walking and running path consisting of LED tiles in a public park.

\section{Temporary high-tech sport facilities}

Temporary high-tech facilities target athletes and often act as marketing events for international sports brands. These innovative pop-up environments make impressive use of technology, combining multiple sensors, and providing a unique user experience mainly focused on performance.

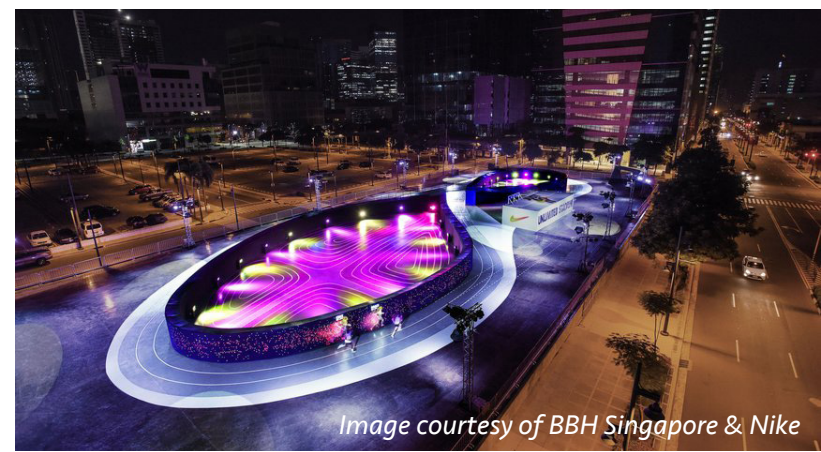

Nike Unlimited Stadium [2]

Nike Unlimited Stadium, described as the world most innovative training environment, tracks a runner's lap time using hyper-accurate Radio-frequency identification. The next lap, your avatar appears, running your previous time to beat. It thus challenges you to keep bettering your best

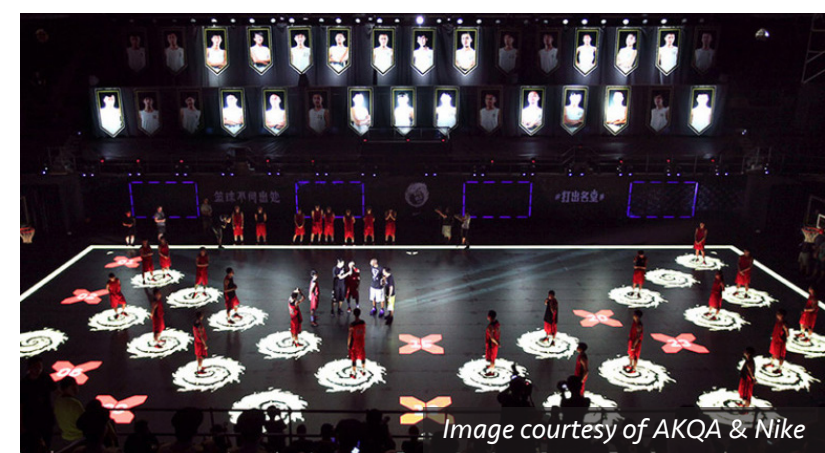

Nike Rise House of Mamba [1]

House of Mamba is a full-sized LED basketball court for the NIKE RISE basketball tour which took place across China. It utilizes motion-tracking and reactive LED visualization to train and challenge the players through authentic drills based on Kobe Bryant's training.

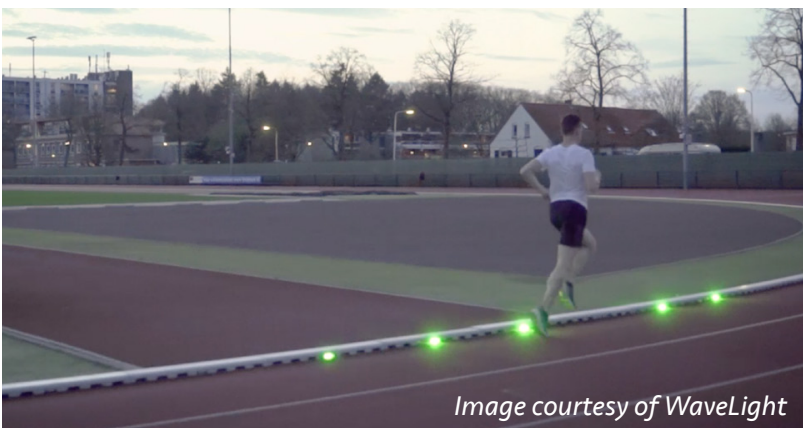

\section{\#Wavelight [35]}

\#WaveLight is an electronic pace-setter guiding runners on time, speed and interval. Easy to install on existing and new athletics tracks, it comprises of $400 \mathrm{LED}$ lights placed in the drainage covers.

\section{Active Outdoor Office Infrastructure}

Active office environments are designs located in the surroundings of office buildings, with the intention to trigger physically active ways of working.

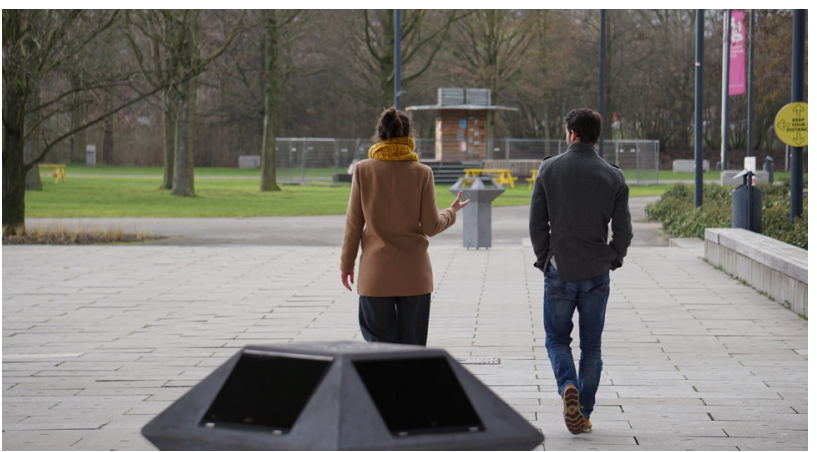

The Hubs [10]

Along a route for walking meetings, a network of Hubs supports work-related tasks such as presenting and notetaking. The Hubs facilitate this type of physically active meeting practice by gaining social acceptance within the organisational culture and overcoming obstacles related to walking meetings [11]. 
Interactive Public Installations

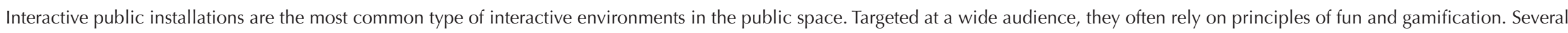

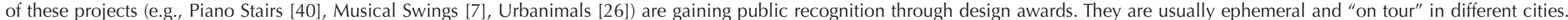
Reflecting on their transformative qualities, it appears that their user experience primarily relies on a novelty and stimulation factor, which might fade away across time.

Piano Stairs [40]

The iconic Piano Stairs project by the Fun Theory (2009) in Stockholm, Sweden nudges people into taking the stairs rather than the escalator

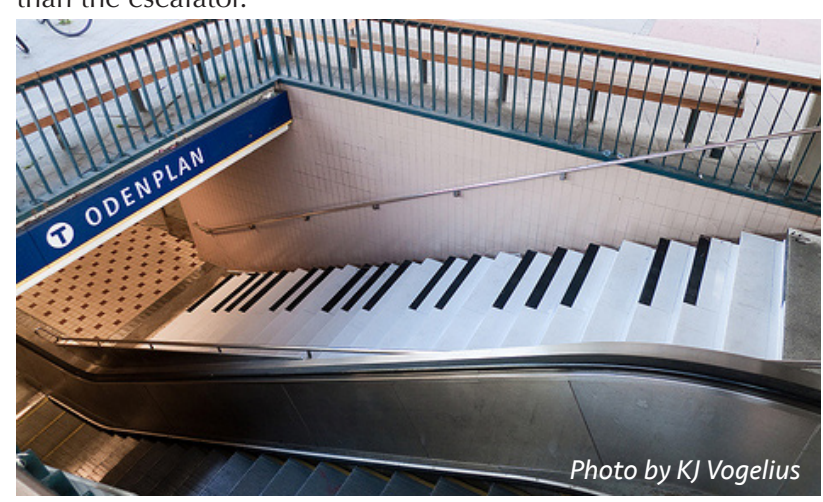

Stride [25]

Stride is a student project composed of a forest of poles, featuring interactive stepping stones. When pressure is detected on a stone, the step lights up and plays a sound.

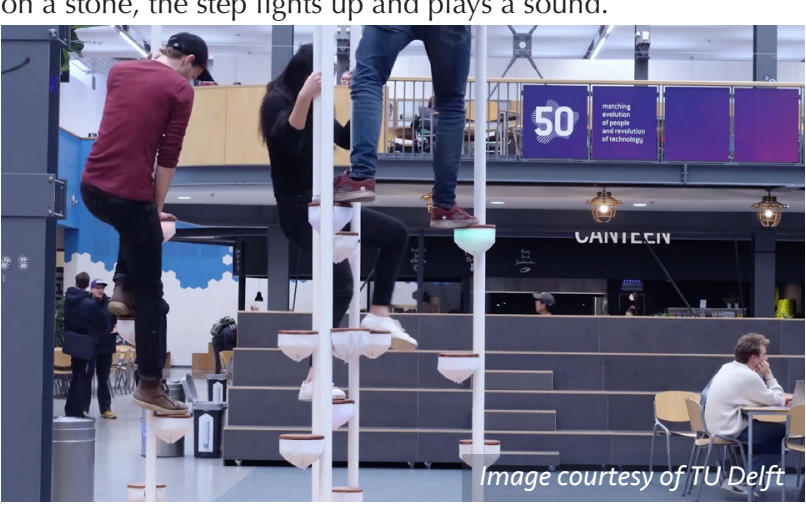

\section{Urbanimals [26]}

These interactive projected animals by LAX encourage to explore the city and play with them, invoking activeness and creativity.

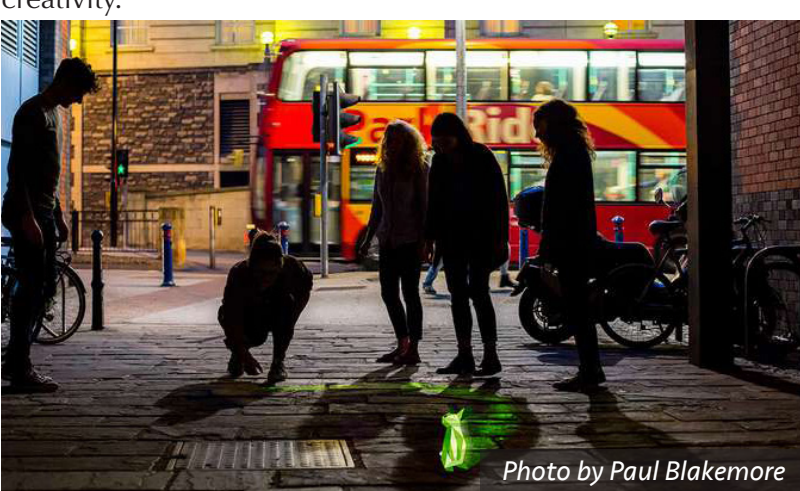

Musical Swings [7] \& the Pearl Divers [8]

Musical Swings and Pearl Divers are interactive installations, designed by Daily Tous les Jours, which invite passerby to make music together with their entire bodies. They represent an emergent field of practice combining technology, storytelling, performance and placemaking.
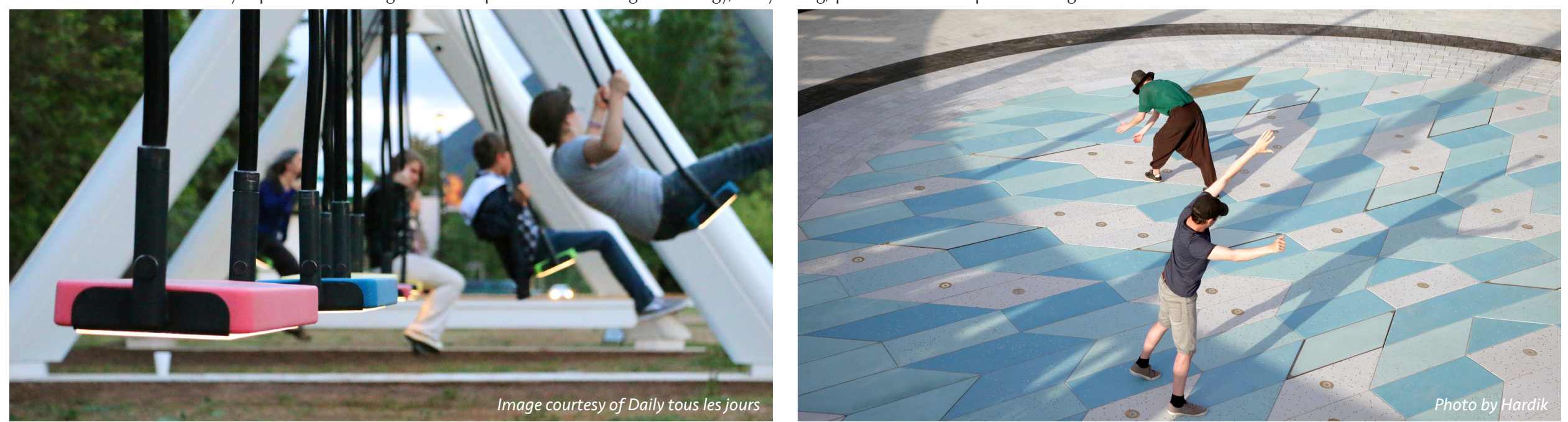


\section{DESIGN EKPLORATIONS}

The second part of our design space exploration focused on ideation and sketches of interActive environments, mostly related to walking and running in urban environments, based on literature and design research and explorations from Industrial Design students and researchers projects over the last two years. As this design activity was exploratory in nature, aimed at mapping out the design space of interActive environments, most of these concepts remained at the conceptualisation stage and a selection only was further developed into prototypes (see Design cases). Reflecting back, we used affinity diagramming to classify the sketches into themes (see also Figure B, p.12) and share the insights we gained from these explorations. Illustrative examples are depicted, some overlapping between several levels of analysis. Further reflections on domains not represented in the sketches are suggested.

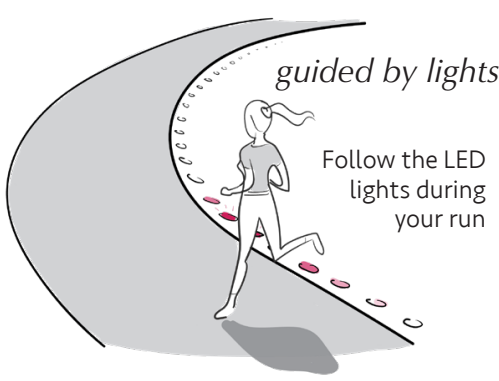

smell your progress

Rose! I increased

my performance

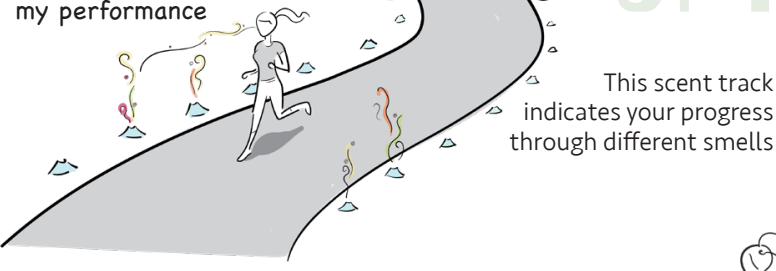

shiny poles
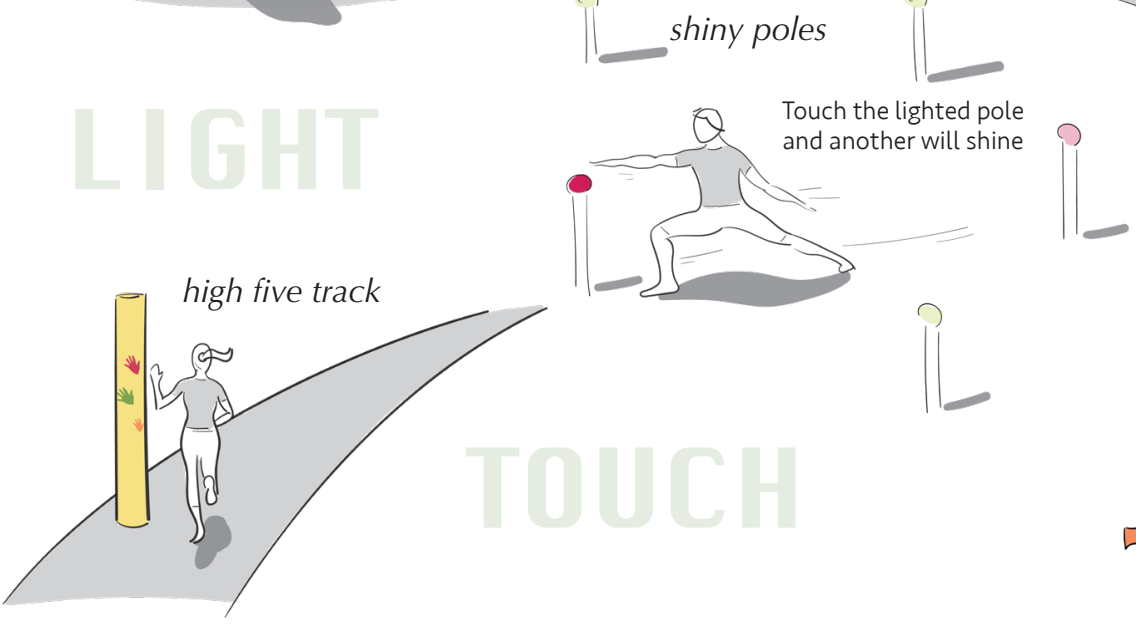

Give me five!

Haptic and visual

feedback encourage

runners after each lap

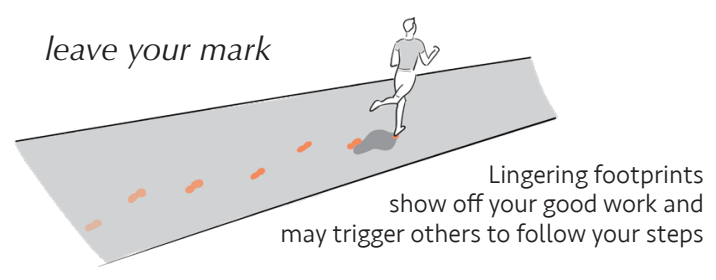

\section{INTERACTION MODALITY}

We first can distinguish several channels of sensory input/output between the environment and the user. The most common interaction modalities were the use of auditory and visual feedback. In line with its predominance in the benchmark, light (using LEDs) tends to be the first idea coming to the mind of designers. It is undeniably a relevant and less intrusive type of feedback in outdoor environments, as compared to sound or smell, but often less visible on a bright day. In our sketches, sound is explored in relation to storytelling, mindfulness and music, which is a common element in recreational running [18], as well as for motivation and guidance. In the storywalking concept for instance, you would listen to a story as you walk to the next waypoint. While being a popular modality used in running-related smartphone apps or in the practice of runners simply listening to their favorite playlist, sound seems rarely encountered in interActive environments. Of course, it is a somewhat disturbing modality in the public space, which could cause nuisances or privacy concerns. Yet there might be intriguing opportunities there too: sound attracts attention, creates a specific ambiance and might stimulate social exchanges and shared user experiences.

Haptic feedback is used to augment the experience or bring a fun element to it. Way less common is the use of smell, only present in a couple of sketches where the designers forced themselves to explore all human senses. The 'smell your progress' concept for instance suggests to use a variety of scents to represent success and performance. Olfactory feedback, while interesting, currently seems challenging to achieve in outdoor environments and might even compete with natural pleasant scents (e.g., freshly cut grass, rain, forest). Designers might get inspired by the use of scents in the field of marketing and retail, where numerous investigation have been made on how it impacts consumer experiences and nudges them into buying behaviors. Translated to the exercising area, one could attract walkers or runners to the next milestone by the use of smell, just like bakeries attract consumers with the irresistible smell of freshly baked bread or pastries. The last of our five senses, taste, was considered yet remained absent from the sketches collected. Rare examples of designs in the field of sports make use of this modality, as Tasty Beats [19] or Edipulse (turning physical activity into chocolates) [20]. Finally, designers of interActive environments can also make use of senses related to the vestibular system, such as gravity, movement and balance. 


\section{INTERVENTION STRATEGY}

Designed environments make use of various intervention strategies, in order to create a positive experience or to trigger behavior change and nudge people into moving.

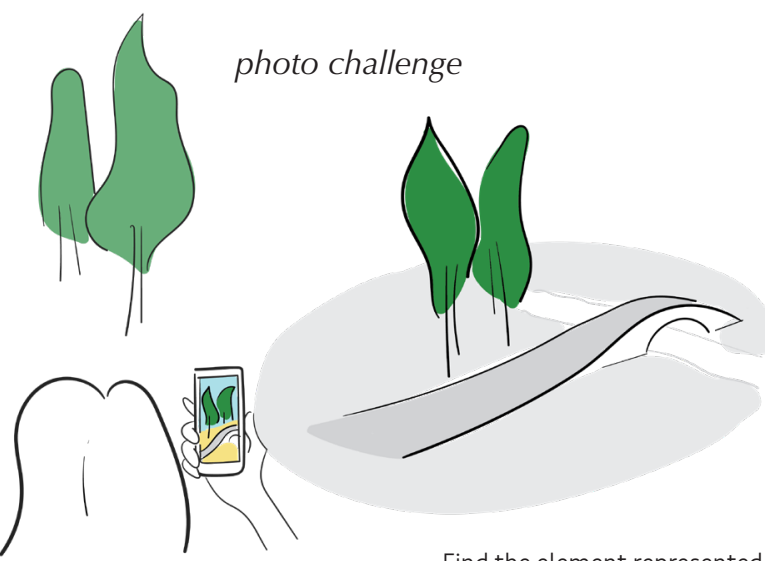
take a picture and validate via image recognition
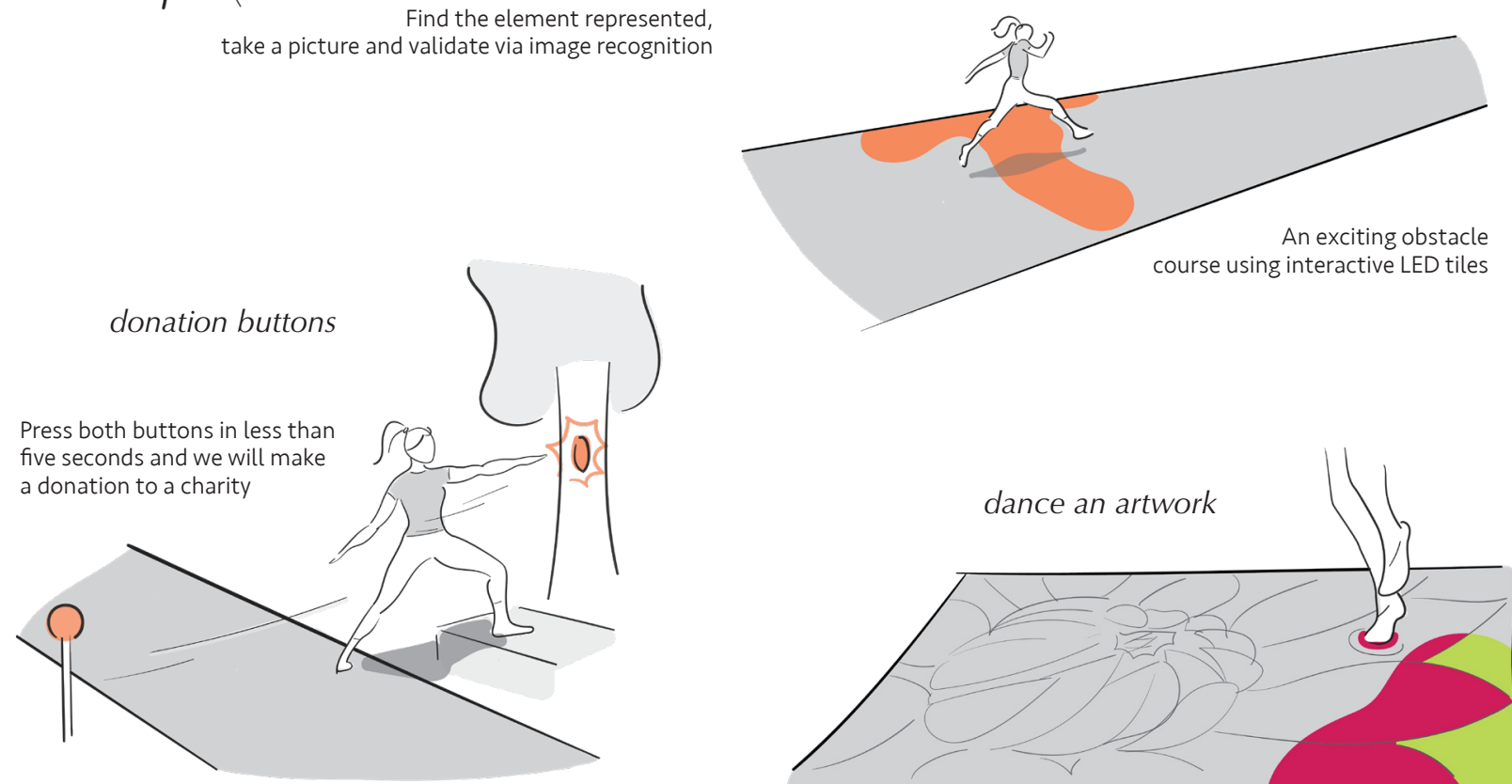
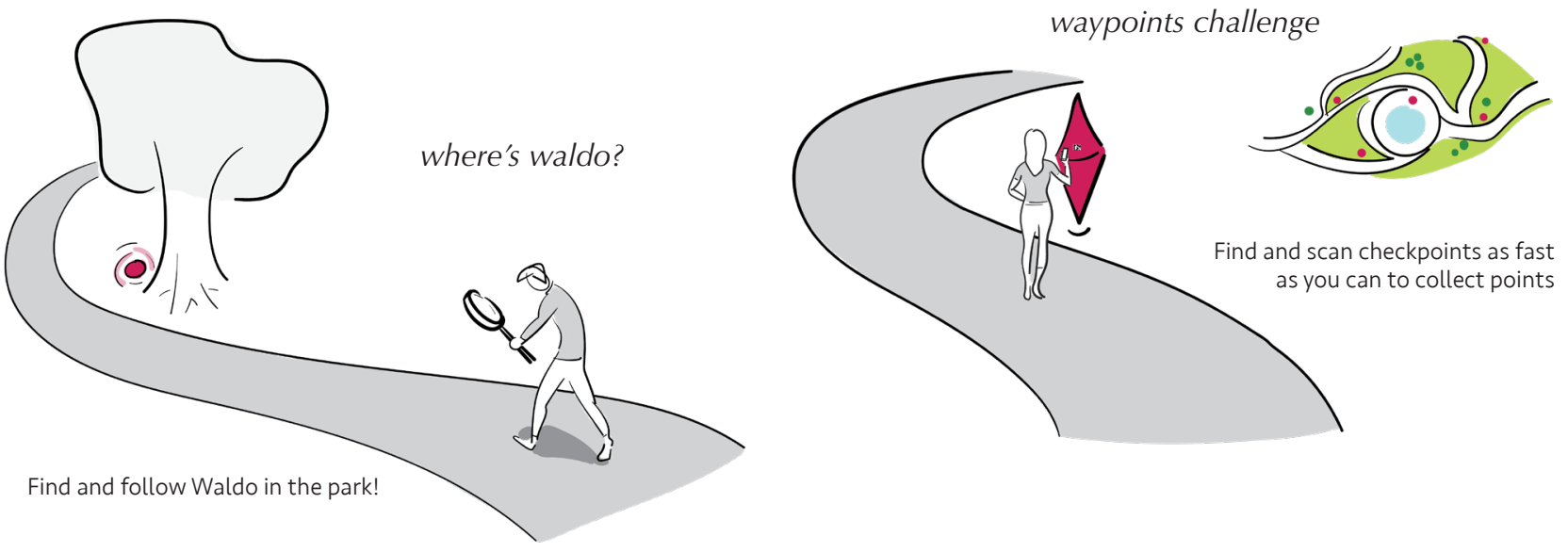

\section{Fun/Gamification}

The most common explored strategy was the use of fun or gamified elements. Considering recreational sport as a leisure activity, these concepts highlight ways to use interactive technology to design playful experiences. Some concepts include challenges in order to stimulate exploration of the environment (e.g., waypoints challenge or photo challenge, where's Waldo?), while others link the activity to charitable causes (e.g. making a donation) potentially during pop-up sponsored events. Other concepts were directly inspired by popular games, such as 'the floor is lava' or 'where's Waldo?'. Finally some more stationary (as in, located at a single place in the urban park) forms of art installations can contribute to the attractiveness of the environment and stimulate people's creativity (e.g., dance an artwork). These are in line with the installations showcased in the benchmark section.

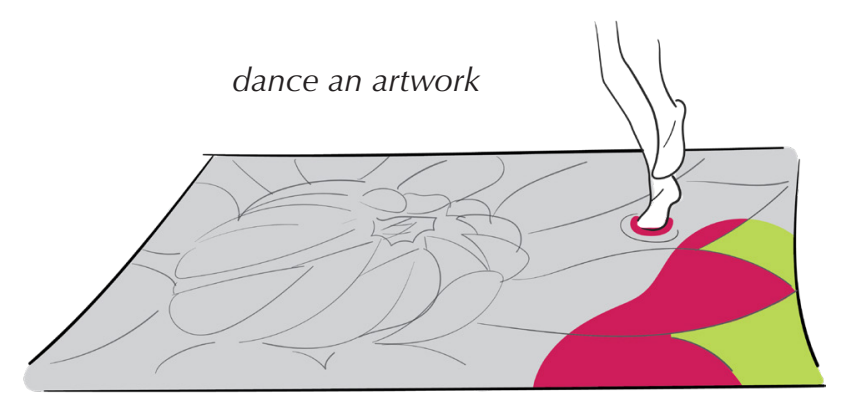

Dance to add color to this artwork, an interactive mandala coloring experience

Various technological supports were envisioned to design these experiences: to log in, the use of RFID tags, QR codes or apps using geolocalization; to interact, the use of pressure sensors in LED panels or image recognition.

This strategy is particularly inclusive to various age ranges, as playful elements might appeal to a wide audience and also triggers social experiences. Existing gamified outdoor environments are usually targeting children, so there is an interest in designing interventions beyond this target group. One limitation however is that the novelty effect of some of these concepts might fade over time. 


\section{Performance / Competition}

Besides leisure use, a number of sketches from our explorations used competitive or performance-related elements. These use mastery and the need for competence as a main trigger for engagement. On the technical side, the ideation focused on running training such as cadence, interval training or adequate foot strikes (e.g., musical cadence training, foot strikes or tempo indicator). Other concepts made use of competitive elements, attempting to make users train faster or harder (e.g., dilemma, race to the finish line, or fast track).

These concepts sometimes require additional inputs, such as data from smartwatches or exercising apps, especially when the users wish to set personal goals or keep track of their progress over time. Exploring these options led to discussions about the benefits of personalization of these experiences. More specifically, which forms of personalization could be suitable for the design of InterActive environments where the main focus stays on a public installation that is by essence shared, and not having access to personal data about its users.

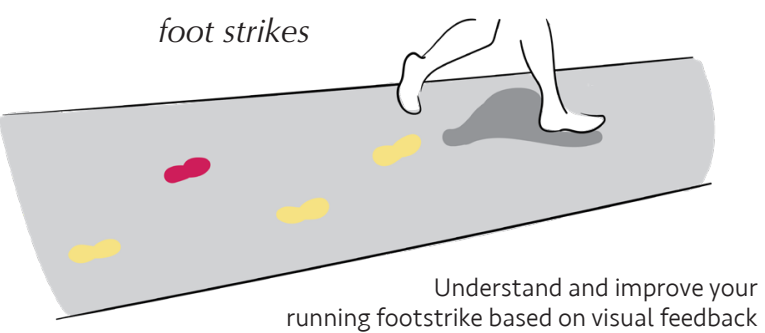

reverse escalator

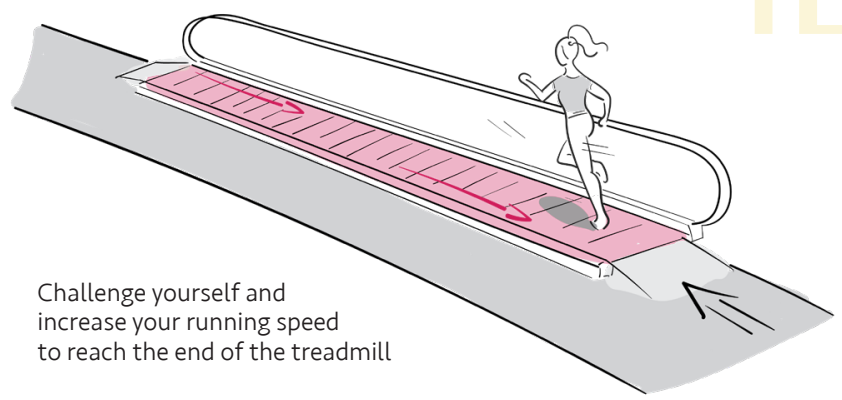

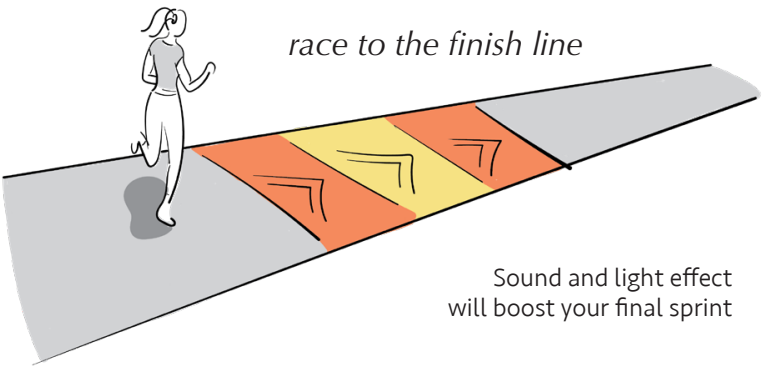
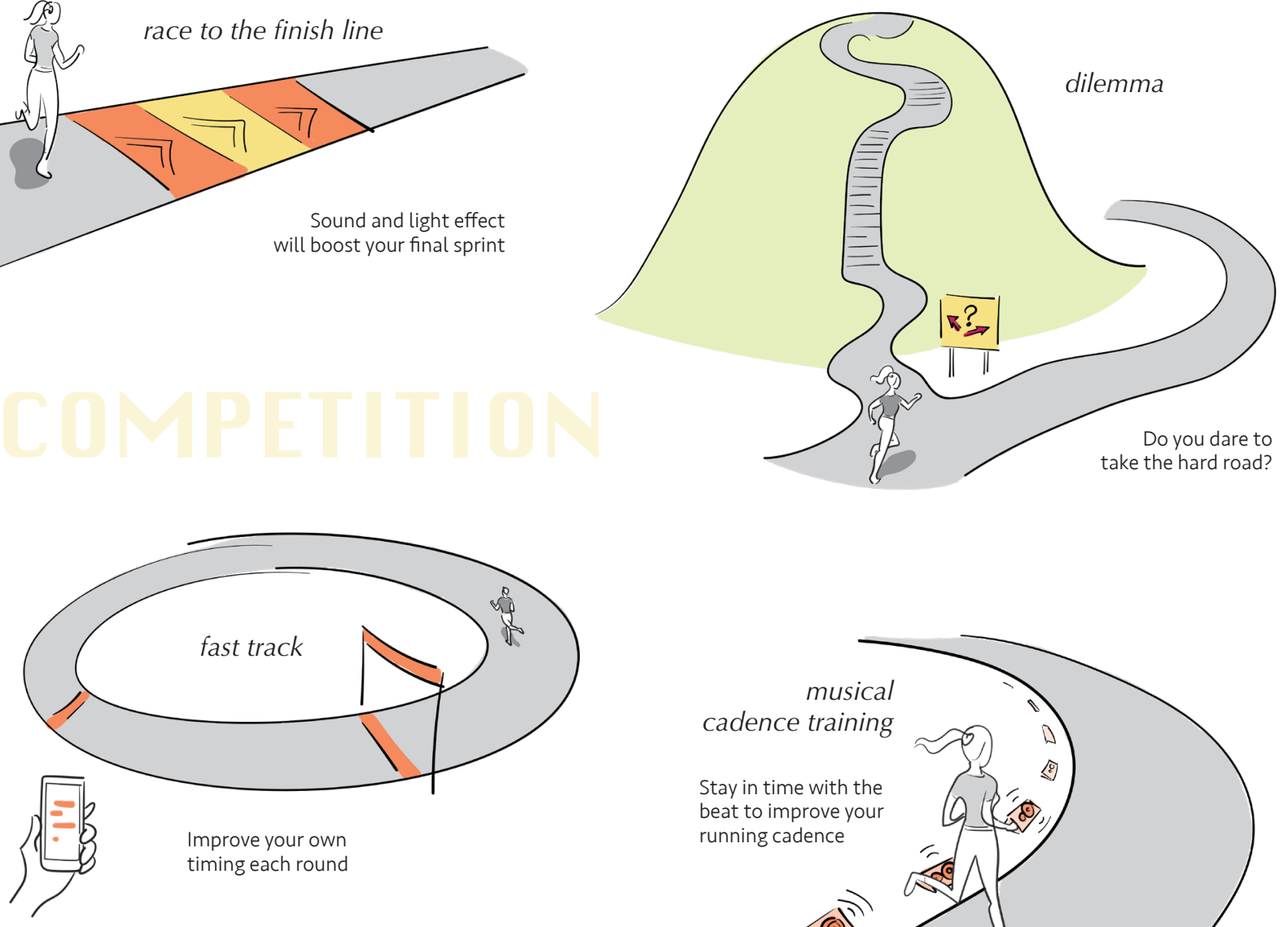
cadence training

Stay in time with the beat to improve your running cadence

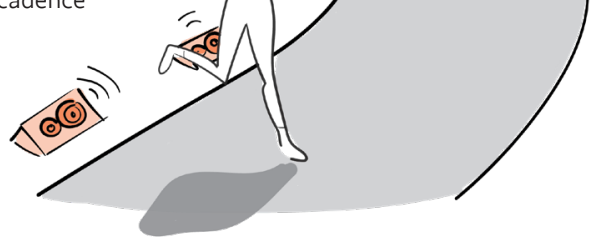




\section{Social Support}

Despite a rather individualistic view on outdoor recreational physical activity, our explorations also include sketches linked to social support. This is mostly done through a virtual representation of a supportive crowd (the clapping track), or messages from fellow exercisers (message to strangers). Some concepts adopted a tailored approach to support, by customizing supporting messages to individuals (personal billboard).

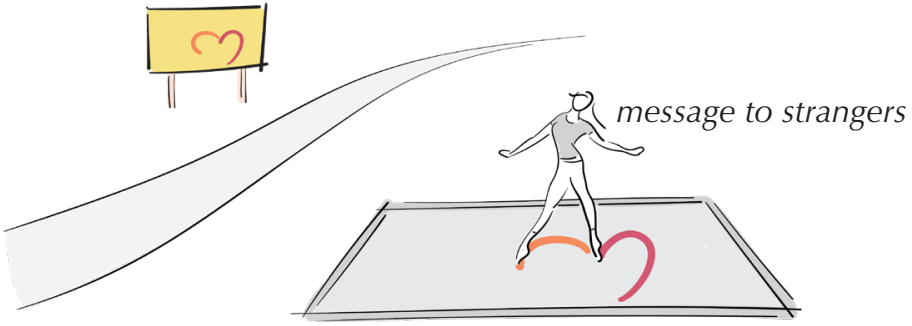

Sketch a message or emoji with your body to encourage future runners
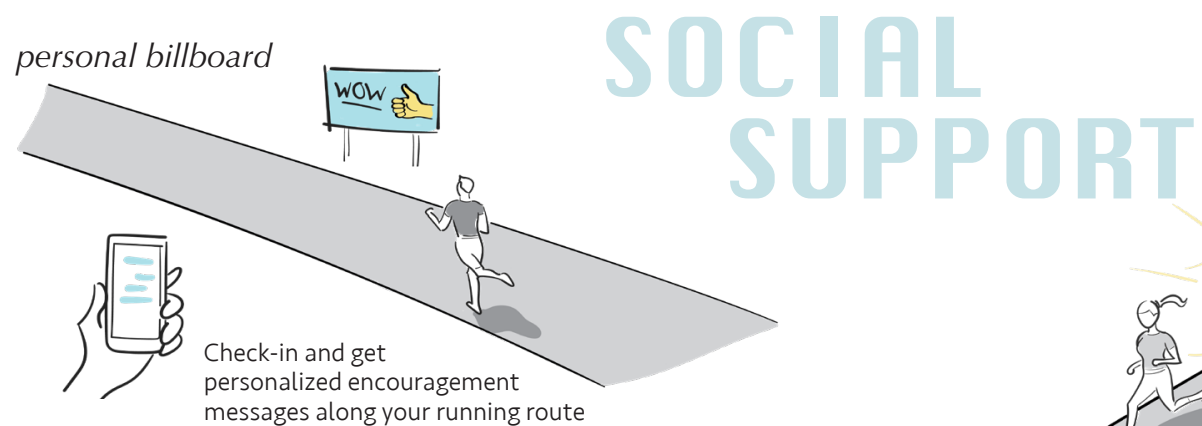

tunnel of sunlight

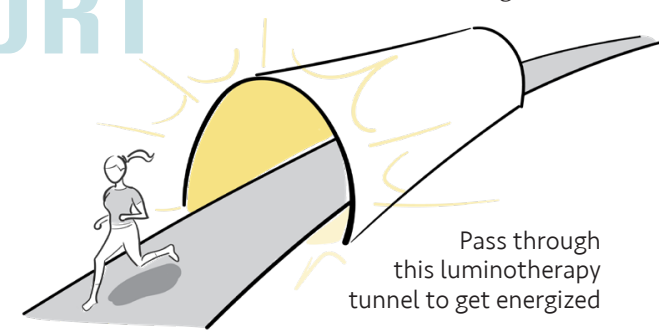

here comes the sun
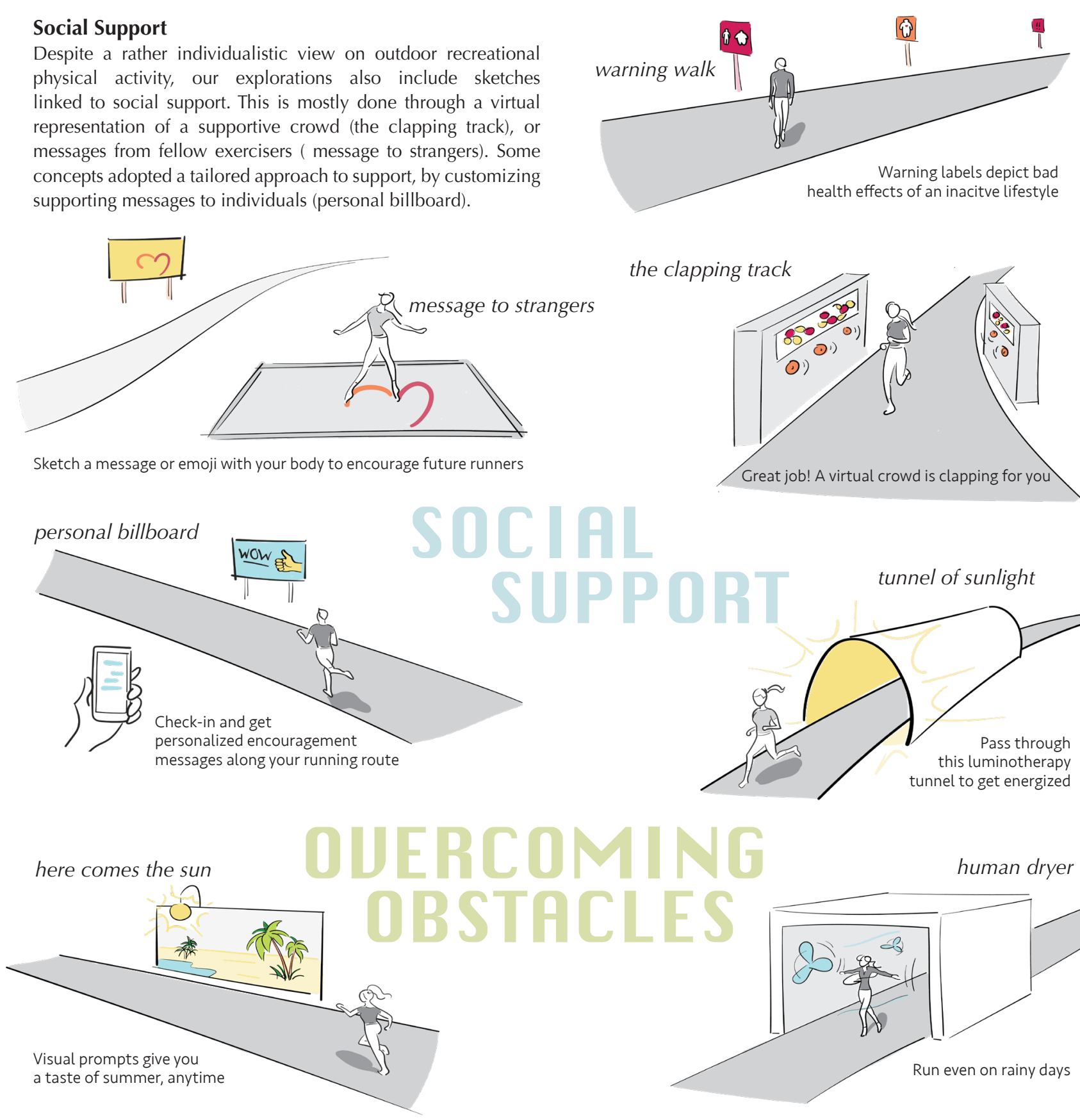

the clapping track

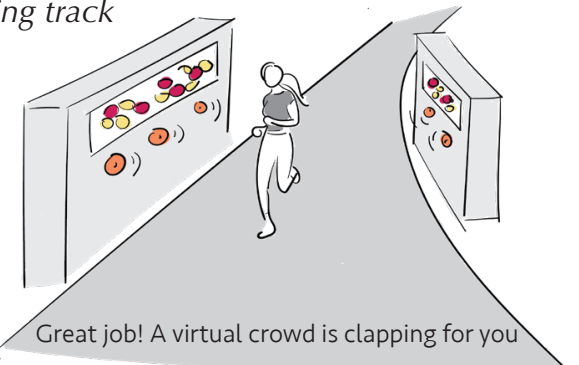

human dryer
PROIOCATIUE
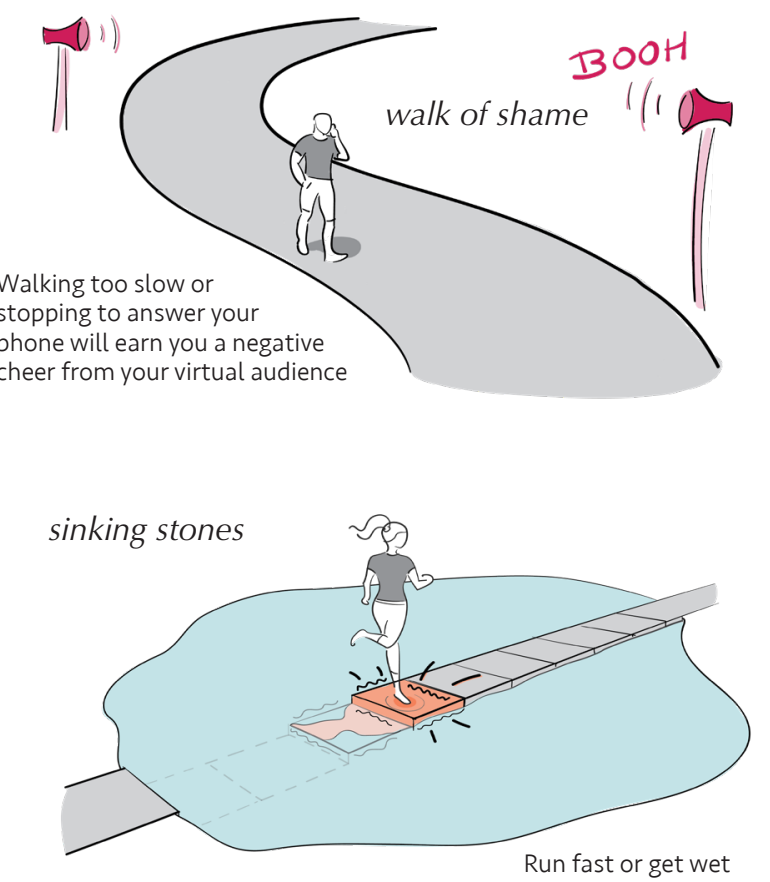

\section{Miscellaneous}

Finally, some of the sketches were harder to categorize and presented out-of-the-box ideas meant at pushing the boundaries of the design space. These covered aspects of convenience meant to overcome the obstacles related to outdoor activity: what about a human-size dryer to invite outdoor running even on rainy days? or a luminotherapy tunnel to get energized even when there is no sunlight? Starting from the reward vs. punishment idea, some concepts adopted a more provocative design perspective, by shocking (warning walk), shaming (walk of shame) or troublemaking (sinking stones). The idea of sense deprivation (e.g., walk in the dark), in opposition to the use of the different human senses as a modality for design, also falls on the provocative side. 


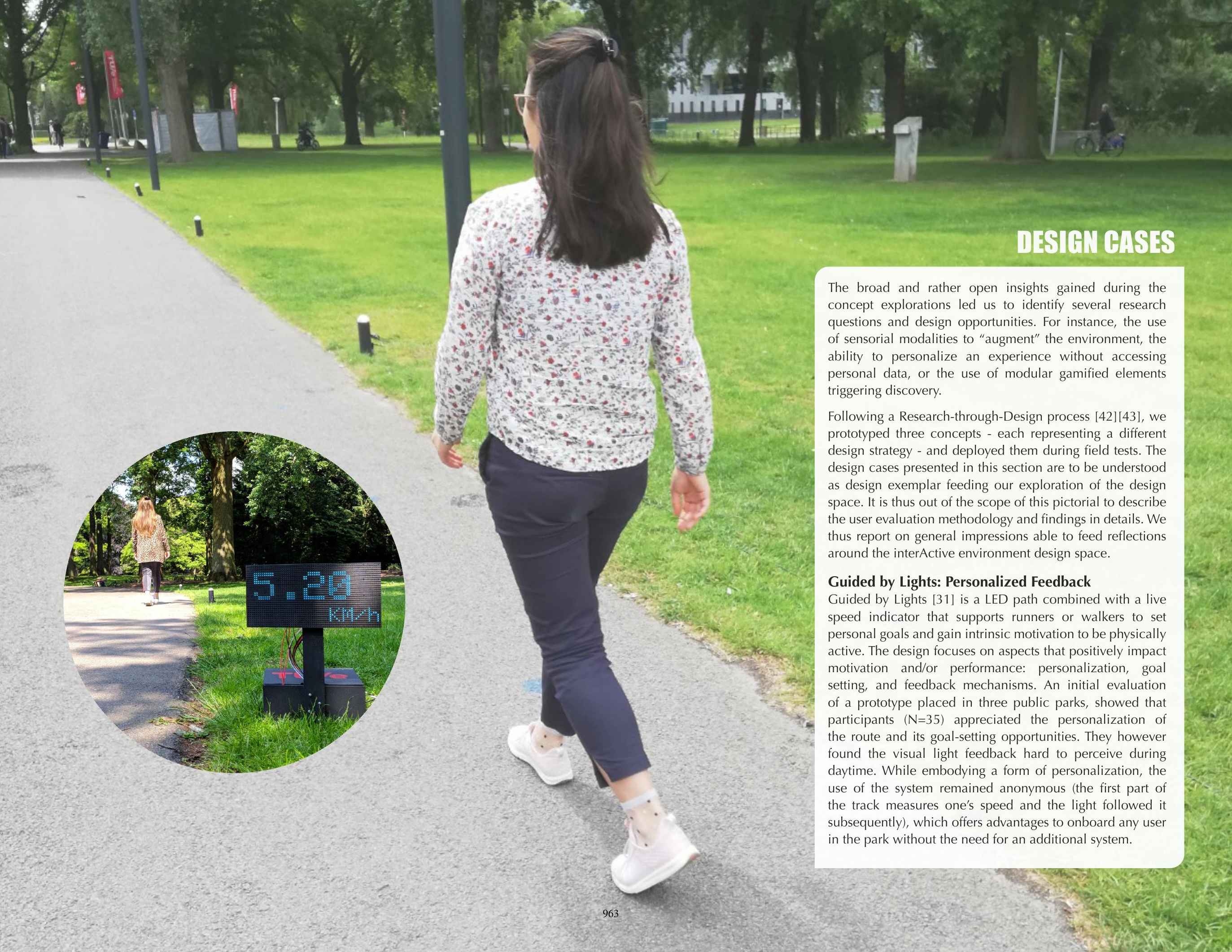




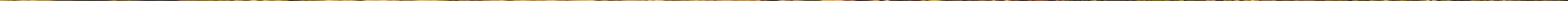




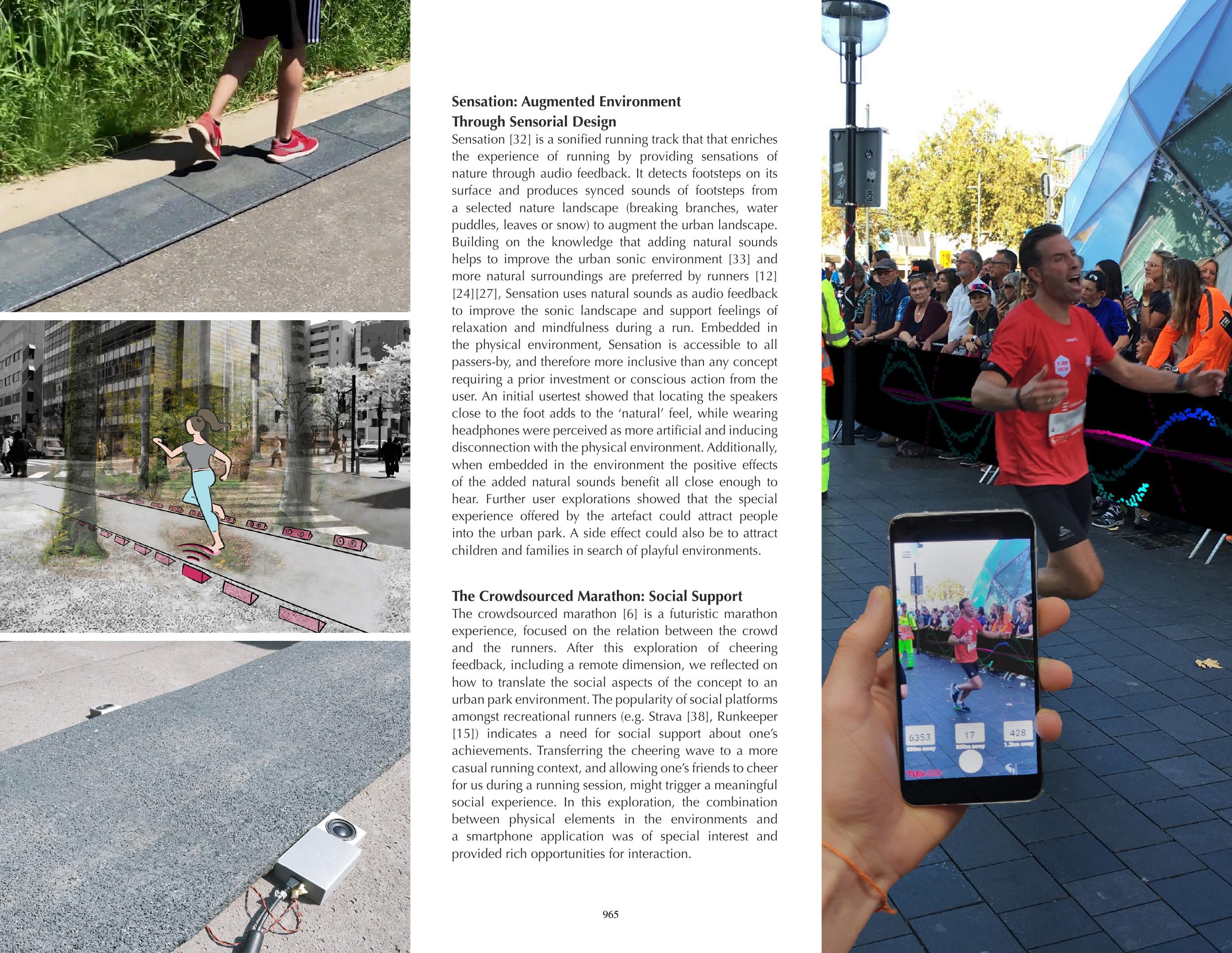




\section{REFLETIONS}

In this exploration we analyzed benchmarked projects, exploratory sketches and design cases, with a specific focus on interaction modalities, intervention strategies and the technological opportunities and challenges. The present work proposes an initial classification of the design space of interActive environments. It does not claim to present a comprehensive list of all possible interactions, intervention levels or technologies, but the examined examples highlight a number of interesting insights meant to inspire researchers and designers. Through our benchmark and experts interviews, we noted that examples of truly interactive urban environments are somewhat scarce. Urban spaces and especially public parks offer a lot of low tech equipment (e.g. calisthenics equipment, cycle lanes) with installations often focused on children (e.g., playground design). This is in line with studies reviewing characteristics of urban parks associated with park use and physical activity [27] [30]. High-tech interactive sport installations [1][2] appear as ephemeral initiatives, initiated by sports brands for branding purposes. They impress by their innovativeness, yet seem hard to fund and maintain by public authorities. Similarly, artsy public installations triggering movement [8][7] attract a lot of attention from the public and the media thanks to their high creativity level, yet they also fail to sustain and scale up. An interesting question is: How can we translate the poetry and engagement created by these installations to a sustained use in public parks?

From the classification matrix of our exploratory sketches (Figure B) and design use cases, we see opportunities to explore the richness of interaction modalities beyond the common visual light feedback. Even using LED technologies, creative freedom remains vast. Other affordable sensors offer new design opportunities: RFID tags, bluetooth beacons, pressure sensors and more. Many of the concepts we explored involved a network of modular elements wirelessly connected to each other, locally or via the cloud. This enables more integrated, hollistic solutions for a harmonized experience, unconstrained by the scale of the urban public space.

The increasing amounts of both user-generated and environmenta data at our disposal provide new insights into personal behavior and preference. Combined with technology, this data can also be used to tailor users' experiences, even in the urban space. Despite the variety and availability of sensors, in this exploration of the design space of interActive environments we see a limited use of the data they provide. Mainly used to trigger a direct response, usually in the form of pre-set visual or auditory feedback, user data is not further processed or utilized. Following the recent

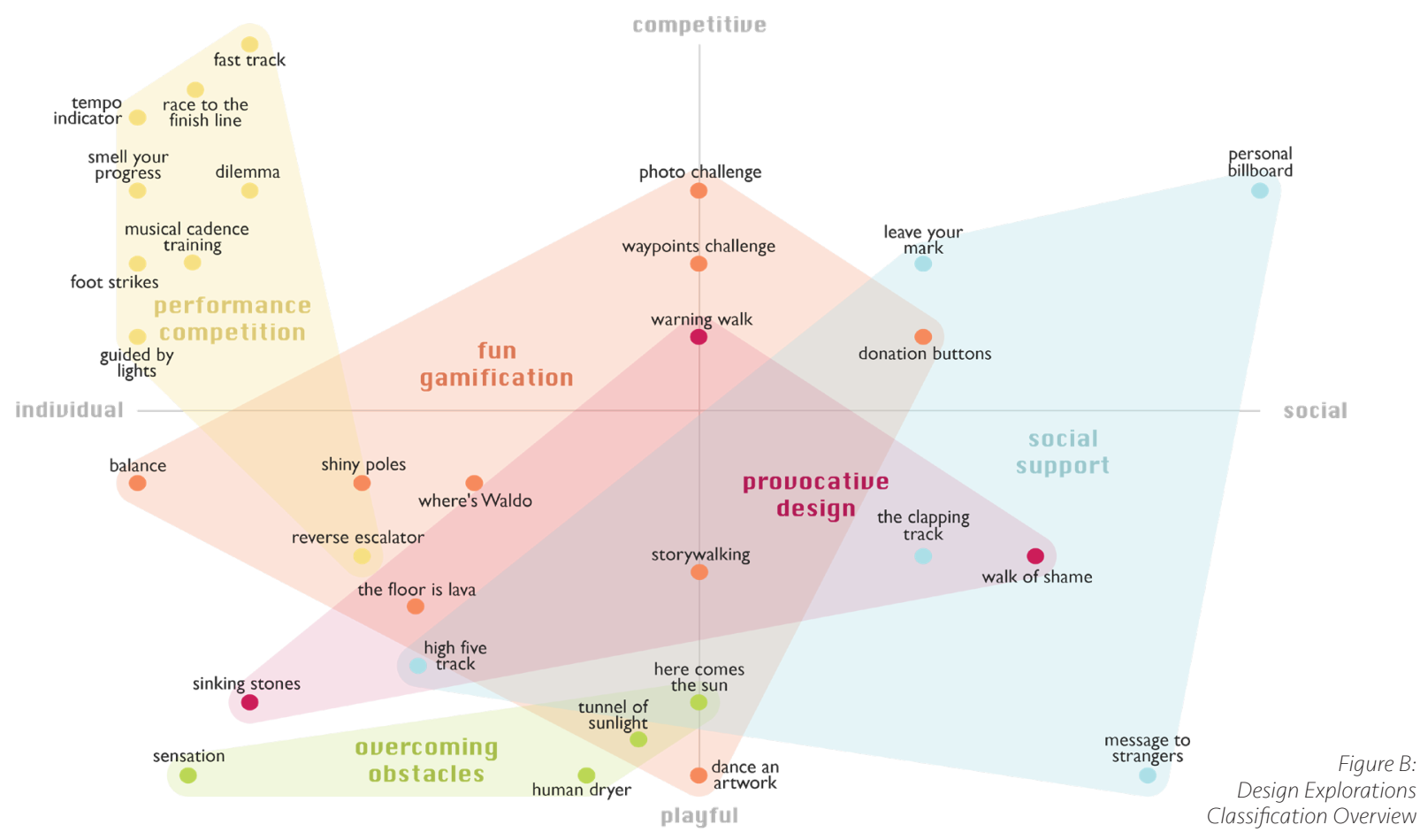

'Data-enabled design' approach by van Kollenburg en Bogers [5], data could be used as a creative material to gain user insights trigger innovative ideas within design processes. Additionally, the opportunities this type of data use provides regarding remote alterations, updates or problem solving of the system are specifically suited for installations placed in the public outdoor space. While privacy is obviously a key concern and endeavor, especially in the public space context, user-generated data could support the design of tailored interventions which are importan in the domain of behavior change.

With their technology embedded in the physical environment interActive environments have the potential to reach everyone in their vicinity, without any prior investment required from the use to benefit from the experience. This makes these intervention much more inclusive than many other available technologies to increase physical activity, even for the hard-to-reach group of people who are not consciously trying to change their inactive routines. Based on the limited number of more permanen installations we encountered, keeping users engaged in the long run might however prove more challenging. Future reflections could revolve around using the potential of technology to personalize these interactions [37] and the need for adjusted and more interdisciplinary approaches that will be needed to design these truly interActive environments.

\section{BONGLUSION}

In this pictorial, we explored the design space of interActive urban environments through a benchmark, sketches, and designed artefacts. This analysis, inspired by the authors' own experiences researching and designing interActive environment is a relevant and timely contribution to consider how technology can help understand and shape human behavior in urban space. We envision the present design space to create a base for discussing challenges and issues related to this topic and to provide inspiration for designers and practitioners.

\section{ACKNOWLEDGEMEITS}

We thank Jasmijn Verhoef, Jelle Neerhof \& Larno Visser for their by Operational Program South Netherlands ERDF 2014-2020. input. This research is part of theVitality Living Lab project, financed 


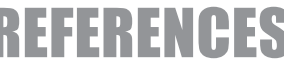

[1] AKQA. 2014. Nike RISE House of Mamba: the world's first interactive LED basketball court. Retrieved January 26, 2021 from https://www.akqa.com/work/nike/rise/

[2] BBH Singapore \& Nike. 2017. NIKE's Unlimited Stadium: The World's most Innovative Running Track. Retrieved February 3, 2021 from https://www.bartleboglehegarty.com/nike-unlimited-stadium

[3] Shlomo Berkovsky, Jill Freyne and Harri OinasKukkonen. 2012. Influencing individually: Fusing personalization and persuasion. ACM Transactions on Interactive Intelligent Systems 2, 2 (2012). DOI:https:// doi.org/10.1145/2209310.2209312

[4] Steven N. Blair. 2009. Physical inactivity: The biggest public health problem of the 21 st century. British Journal of Sports Medicine 43, 1 (2009), 1-2.

[5] Sander Bogers, Joep Frens, Janne Van Kollenburg, Eva Deckers, and Caroline Hummels. 2016. Connected baby bottle: A design case study towards a framework for data-enabled design. DIS 2016 - Proceedings of the 2016 ACM Conference on Designing Interactive Systems: Fuse (2016), 301-311. DOl:https://doi. org/10.1145/2901790.2901855

[6] B. van Bunder, B.A.S. Fok, S.C. Ooms, and S.T.B. Wilting. 2018. The crowdsourced marathon. Winner Best Design at Design Marathon Eindhoven 2018. Retrieved from https://innovationorigins.com/design-marathongenerating-ideas-for-the-most-innovative-marathon-inthe-world/

[7] Daily tous les jours. 2011. Musical Swings - An exercise in cooperation. Retrieved January 26, 2021 from www.dailytouslesjours.com/en/work/musical-swings

[8] Daily tous les jours. 2019. The Pearl Divers - Dancing with your shadow. Retrieved January 26, 2021 from https://www.dailytouslesjours.com/en/work/musicalshadows

[9] Joan Dallinga, Mark Janssen, Joey van der Bie, Nicky
Nibbeling, Ben Krose, Goudsmit, Jos, Carl Megens, Marije Baart de la Faille-Deutekom, and Steven Vos. 2016. De rol van innovatieve technologie in het stimuleren van sport en bewegen in de steden Amsterdam en Eindhoven. Vrijetijdstudies 2 (2016), 43-57.

[10] Ida Damen, Anika Kok, Bas Vink, Hans Brombacher, Steven Vos, and Carine Lallemand. 2020. The hub: Facilitating walking meetings through a network of interactive devices. DIS 2020 Companion - Companion Publication of the 2020 ACM Designing Interactive Systems Conference (2020), 19-24. DOI:https://doi. org/10.1145/3393914.3395876

[11] Ida Damen, Carine Lallemand, Rens Brankaert, Aarnout Brombacher, Pieter Van Wesemael, and Steven Vos. 2020. Understanding Walking Meetings: Drivers and Barriers. In CHI '20: Proceedings of the $2020 \mathrm{CH}$ Conference on Human Factors in Computing Systems, 1-14. DOI:https://doi.org/10.1145/3313831.3376141

12] Ineke Deelen, Mark Janssen, Steven Vos, Carlijn B.M. Kamphuis, and Dick Ettema. 2019. Attractive running environments for all? A cross-sectional study on physical environmental characteristics and runners' motives and attitudes, in relation to the experience of the running environment. BMC Public Health 19, 366 (2019). DOI:https://doi.org/10.1186/s12889-019-6676-6

[13] Robby Van Delden, Alejandro Moreno, Ronald Poppe, Dennis Reidsma, and Dirk Heylen. 2017. A thing of beauty: Steering behavior in an interactive playground. In Conference on Human Factors in Computing Systems - Proceedings, 2462-2472. DOI:https://doi. org/10.1145/3025453.3025816

[14] Peggy Edwards and Agis D. Tsouros. 2008. A healthy city is an active city: a physical activity planning guide. World Health Organisation Regional Office for Europe, Copenhagen, Denmark.

[15] Fitness Keeper Inc. 2008. Runkeeper. [Best run tracking and mapping]. Retrieved from www.runkeeper.com
[16] Michelle L. Granner, Patricia A. Sharpe, Brent Hutto, Sara Wilcox, and Cheryl L. Addy. 2007. Perceived individual, social, and environmental factors for physical activity and walking. Journal of Physical Activity and Health 4, 3 (2007), 278-293. DOI:https://doi. org/10.1123/jpah.4.3.278

[17] Gregory W. Heath, Diana C. Parra, Olga L. Sarmiento, Lars Bo Andersen, Neville Owen, Shifalika Goenka, Felipe Montes, Ross C. Brownson, Jasem R. Alkandari, Adrian E. Bauman, Steven N. Blair, Fiona C. Bull, Cora L. Craig, UIf Ekelund, Regina Guthold, Pedro C. Hallal, William L. Haskell, Shigeru Inoue, Sonja Kahlmeier, Peter T. Katzmarzyk, Harold W. Kohl, Estelle Victoria Lambert, I. Min Lee, Grit Leetongin, Felipe Lobelo, Ruth J.F. Loos, Bess Marcus, Brian W. Martin, Michael Pratt, Pekka Puska, David Ogilvie, Rodrigo S. Reis, James F. Sallis, and Jonathan C. Wells. 2012. Evidence-based intervention in physical activity: Lessons from around the world. The Lancet 380, 9838 (2012), 272-281. DOI:https://doi.org/10.1016/S01406736(12)60816-2

[18] Jasmin C Hutchinson. 2017. Running with Music. AMAA Journal 30, 1 (2017), 13-15

[19] Rohit Ashok Khot, Jeewon Lee, Deepti Aggarwal, Larissa Hjorth, and Florian "Floyd" Mueller. 2015. TastyBeats: Designing Palatable Representations of Physical Activity. In CHI '15: Proceedings of the 33rd Annual ACM Conference on Human Factors in Computing Systems, 2933-2942. DOI:https://doi. org/10.1145/2702123.2702197

[20] Rohit Ashok Khot, Ryan Pennings, and Florian Mueller. 2015. EdiPulse: Turning physical activity into chocolates. In CHI '15: Proceedings of the 33rd Annual ACM Conference on Human Factors in Computing Systems, 331-334. DOI:https://doi. org/10.1145/2702613.2725436

[21] Harold W. Kohl, Cora Lynn Craig, Estelle Victoria Lambert, Shigeru Inoue, Jasem Ramadan Alkandari, Grit 
Leetongin, and Sonja Kahlmeier. 2012. The pandemic of physical inactivity: Global action for public health The Lancet 380, 9838 (2012), 294-305. DOI:https:// doi.org/10.1016/S0140-6736(12)60898-8

[22] Małgorzata Kostrzewska. 2017. Activating Public Space: How to Promote Physical Activity in Urban Environment. IOP Conference Series: Materials Science and Engineering 245, 5 (2017). DOI:https://doi. org/10.1088/1757-899X/245/5/052074

[23] Anne Krefis, Matthias Augustin, Katharina Schlünzen, Jürgen Oßenbrügge, and Jobst Augustin. 2018. How Does the Urban Environment Affect Health and Well-Being? A Systematic Review. Urban Science 2, 1 (2018), 21. DOI:https://doi.org/10.3390/urbansci2010021

[24] Kira Krenichyn. 2006. "The only place to go and be in the city": women talk about exercise, being outdoors, and the meanings of a large urban park. Health and Place 12, 4 (2006), 631-643. DOI:https://doi. org/10.1016/j.healthplace.2005.08.015

[25] Kevin van der Lans, Bianca Lieu, Edward Na, Laura Ot tevanger, Julia Rademaker, Marijn Roelvink, and Luuk Streefkerk. 2020. STRIDE. Retrieved January 26, 2021 from https://interactive-environments.nl/stride/

[26] LAX - Laboratory for Architectural Experiments. 2015 Urbanimals. Retrieved February 5, 2021 from http:// lax.com.pl/portfolio_page/urbanimals/

[27] Gavin R. McCormack, Melanie Rock, Ann M. Toohey, and Danica Hignell. 2010. Characteristics of urban parks associated with park use and physical activity: A review of qualitative research. Health and Place 16, 4 (2010), 712-726. DOI:https://doi.org/10.1016/j.healthplace.2010.03.003

[28] C. Megens, I. Neutelings, B. van Hout, M. Janssen, and S. Vos. 2016. Run!: developing a high tech running path in the park. In SECSI 2016, Proceedings of the Science \& Engineering Conference on Sports Innovation.
[29] Niantic Inc. 2016. Pokémon GO. [Discover Pokemon Worldwide]. Retrieved from https://www.pokemongolive.com

[30] Patrick Norman and Catherine Marina Pickering. 2019 Factors influencing park popularity for mountain bikers, walkers and runners as indicated by social media route data. Journal of Environmental Management 249, november (2019). DOI:https://doi.org/10.1016/j.jenvman.2019.109413

[31] Loes van Renswouw, Carine Lallemand, Bodi Fok, Maaike Jetten, Ayu Ritzema, Heleen Smeets, and Steven Vos. 2020. Guided by Lights : Stimulating Physical Activity through an Adaptive Personal Light System. In Design4Health 2020: Proceedings of the 6th International Conference on Design4Health, Amsterdam, 2020, Lab4Living, Sheffield Hallam University, Amsterdam, Netherlands, Vol 4. p. 68-75.

[32] Loes van Renswouw, Jelle Neerhof, Steven Vos, Pieter van Wesemael, and Carine Lallemand. 2021. Sensation : Sonifying the Urban Running Experience. In $\mathrm{CHI}$ '21 Extended Abstracts: Proceedings of the $2021 \mathrm{CHI}$ Conference on Human Factors in Computing Systems Extended Abstracts, 5. DOI:https://doi.org/https://doi. org/10.1145/3411763.3451788

[33] Timothy Van Renterghem, Kris Vanhecke, Karlo Filipan, Kang Sun, Toon De Pessemier, Bert De Coensel, Wout Joseph, and Dick Botteldooren. 2020. Interactive soundscape augmentation by natural sounds in a noise polluted urban park. Landscape and Urban Planning 194, (2020). DOI:https://doi.org/10.1016/j.landurbplan.2019.103705

[34] James F. Sallis, Ester Cerin, Terry L. Conway, Marc A. Adams, Lawrence D. Frank, Michael Pratt, Deborah Salvo, Jasper Schipperijn, Graham Smith, Kelli L. Cain, Rachel Davey, Jacqueline Kerr, Poh Chin Lai, Josef Mitáš, Rodrigo Reis, Olga L. Sarmiento, Grant Schofield, Jens Troelsen, Delfien Van Dyck, Ilse De Bourdeaudhuij, and Neville Owen. 2016. Physical activity in relation to urban environments in 14 cities worldwide: a cross-sectional study. The Lancet 387, 10034 (2016), 2207-2217. DOI:https://doi.org/10.1016/s01406736(15)01284-2

[35] WaveLight Technologies. 2018. \#WAVELIGHT. [Feel the perfect pace]. Retrieved April 20, 2021 from https://www.wavelight-technologies.com

[36] Six to Start and Naomi Alderman. 2012. Zombies, Run! [Run in the Real World. Become a Hero in Another.]. Retrieved from https://zombiesrungame.com

[37] Constantine Stephanidis, Gavriel Salvendy, Margherita Antona, Jessie Y.C. Chen, Jianming Dong, Vincent G. Duffy, Xiaowen Fang, Cali Fidopiastis, Gino Fragomeni, Limin Paul Fu, Yinni Guo, Don Harris, Andri loannou, Kyeong ah (Kate) Jeong, Shin'ichi Konomi, Heidi Krömker, Masaaki Kurosu, James R. Lewis, Aaron Marcus, Gabriele Meiselwitz, Abbas Moallem, Hirohiko Mori, Fiona Fui-Hoon Nah, Stavroula Ntoa, Pei Luen Patrick Rau, Dylan Schmorrow, Keng Siau, Norbert Streitz, Wentao Wang, Sakae Yamamoto, Panayiotis Zaphiris, and Jia Zhou. 2019. Seven HCl Grand Challenges. International Journal of Human-Computer Interaction 7318, (2019). DOI:https://doi.org/10.1080/10447318.2 019.1619259

[38] Strava Inc. 2009. Strava. [Strava GPS Cycling and Running App]. Retrieved from

[39] Norbert A Streitz. 2007. From Human-Computer Interaction to Human-Environment Interaction: Ambient Intelligence and the Disappearing Computer. In in: Stephanidis C., Pieper M. (eds) Universal Access in Ambient Intelligence Environments. Lecture Notes in Computer Science, vol 4397. Springer, Berlin, Heidelberg, 3-13.

[40] The Fun Theory (initiative by Volkswagen). 2009. Piano Stairs. Retrieved February 5, 2021 from https://www. designoftheworld.com/piano-stairs/

[41] WHO. 2018. Global action plan on physical activity 
2018-2030: More Active People for a Healthier World. World Health Organization, Geneva. DOI:https://doi. org/10.1016/j.jpolmod.2006.06.007

[42] John Zimmerman and Jodi Forlizzi. 2014. Research Through Design in $\mathrm{HCl}$. In Ways of Knowing in $\mathrm{HCl}$, Judith S Olson and Wendy A Kellogg (eds.). Springer New York, New York, NY, 167-189.

[43] John Zimmerman, Jodi Forlizzi, and Shelley Evenson. 2007. Research through design as a method for interaction design research in $\mathrm{HCl}$. $\mathrm{CHI}$ '07: Proceedings of the SIGCHI conference on Human factors in computing systems (2007), 493. DOI:https://doi. org/10.1145/1240624.1240704 